\title{
A Computational Environment for Radiology and Image-Diagnosis Teaching: A Proposal Using Systems Methodology
}

\author{
$\underline{\text { doi:10.3991/ijet.v4i1.651 }}$ \\ M.G.Pinheiro, L.R.Figueiredo, P.M.Azevedo-Marques and J.Elias-Jr \\ University of São Paulo, Ribeirão Preto, Brazil.
}

\begin{abstract}
Defining a computational environment for radiology and image-diagnosis education requires the development of a model that covers the resident doctor's training necessities and creates the mechanisms necessary for the construction of this environment, especially integrating the various systems in use or in development, in a hospital school. This work presents a proposal to define strategies for the creation of a computational environment for radiology and image-diagnosis teaching, specifically aimed towards the education of the resident physician in this area. The Soft Systems Methodology (SSM) was used to elaborate a comprehensive model under a systemic focus and bring up actions for its implementation. Initially, the current radiology teaching structure will be contextualized, and information systems that could be applied to support this type of activity will be discussed. The next step will be the revision of the SSM and the application of each step proposed by this methodology within the medical residency context of a large Brazilian hospital school. This residencyeducation activity survey was performed through interviews, questionnaires and the review of the norms, criteria and minimum requirements for the accreditation of medical residency programs in Brazil. Considering the complexity of the doctor-training environment and the diversity of computer systems under development to support it, the systemic approach helps the understanding and can guide the necessary integration. An integratedenvironment frame, and its action plan, is proposed for radiology and image-diagnosis teaching. Finally, the strategies identified for its implementation are discussed.
\end{abstract}

Index Terms-Computer-Assisted Instruction (CAI), Medical Education, Systems Integration, Systems Methodology.

\section{INTRODUCTION}

Radiology and image-diagnosis teaching is based on training for examinations, the understanding of its principles and the image analysis of real cases. Following the exam, the instructor presents to the student (a) the relationship between the body's anatomy and its respective image, (b) the knowledge of the semiology elements associated with it, and (c) the diagnosis routine.

Radiologists learn diagnostic skills by observing many clinical cases during their training and clinical practice, and their knowledge obtained from visual impression of images with various diseases constitutes the foundation for their diagnosis. However, the instructors - physicians at hospital schools - frequently have limited time and the medical students a less than ideal number of opportunities for the discussion of case studies [1]. Information systems can assist in the training of methods and techniques for the manipulation of the various types of information involved in this application.

Defining a computational environment for radiology and image-diagnosis education requires the development of a model that covers the resident doctor's training necessities and creates the mechanisms necessary for the construction of this environment.

\section{Soft Systems METHOdOLOGy SSM}

The General Systems Theory [2] came about as a reaction to the excessive specialization and fragmentation of the sciences and proposes useful transfers between the many fields of knowledge, as well as an improvement in the communication between specialists. The option for systematic theoretical referential allows viewing the system in its totality, as opposed to reductionist or simplistic analytical outlooks. Such outlooks only consider part of their true objects of study, leaving influences and relationships with other systems and with the environment in which they live aside. For Checkland $[3,4]$, there is also a common purpose or a unit that reasonably contemplates the idea of totality.

The Soft Systems Methodology SSM [3,4] allows for a structured approach to problematic situations. It is composed of seven phases. A diagram with the stages is presented in Fig. 1. This methodology is being used in several areas [5,6], including in the development of information-technology and education models. It presents itself as adequate for the essential definitions that will compose the conceptual model of the environment proposed herein. Its application requires investigating the views of all interested professors, students and staff, and the study/work environment itself, to expose information omission and perception conflicts. The experience of the analyzed hospital school will be used as a basis for this work.

\section{APPLICATION OF THE SSM}

In this section, the seven steps of the SSM will be succinctly presented. The first four stages lead to the construction of the Proposed Conceptual Model, the purpose of this work.

\section{A. Stages 1 and 2 "The Problem Situation"}

In stages 1 and 2 of the SSM, an attempt is made to construct the most complete frame possible of the situation where the fact is perceived as a problem. This is 
done through the registration of the numerous perceptions of the highest possible number of people that assume different roles within the problematic situation. It is necessary to identify the developed tasks, tools and methods that were employed, establish interactions between people/systems, create sketches of the structures/layouts, and conduct informal interviews for essential formulated definitions [5].

With respect to medical residency, in Brazil, the legislation defines the activities for the resident doctor's specialization in radiology and image diagnosis [1]. The National Commission of Medical Residency CNRM and the Brazilian School of Radiology and Image Diagnosis CBR have defined the norms and established the criteria and minimum requirements for the accreditation of medical residency programs [7]. At least $80 \%$ of the radiology resident's activities focus on service training, which consists of the resident's knowledge being applied under supervision in the daily hospital service. The remaining $20 \%$ involves academic activities. These activities include clinical and clinic-radiological anatomy sessions, discussions of scientific articles, clinical laboratory sessions, courses, lectures and seminars. In addition to the specific education in image diagnosis, the themes approached in these activities should also contemplate bioethics, medical ethics, scientific methodology, epidemiology and biostatistics. The training is formally divided into three levels, corresponding to the first, second and third year of medical residency, respectively (R1, R2 and R3 order).

In 2006, over 150 thousand exams with medical images were performed at the hospital. Although it has a large service volume, the Center of Image Sciences and Medical Physics CCIFM only has 28 resident doctors and 6 professors in the radiology and image-diagnosis area [8,9]. The CCIFM doctors are also responsible for the hospital and emergency-unit radiology supervision and protection service, the planning of radiotherapy radiationsource dosage and calibration, and promote quality control for the radio-diagnostic, nuclear medicine and radiotherapy equipment. The training of this group of residents is the object of interest of this study.

In regards to Information Technology, at the hospital there is an internal cable and wireless network with Internet access including the entire image-production service and all professors have computers in their offices. In the Image-Processing Laboratory, LAPIR, twenty computers are shared between the students, professors and technicians.

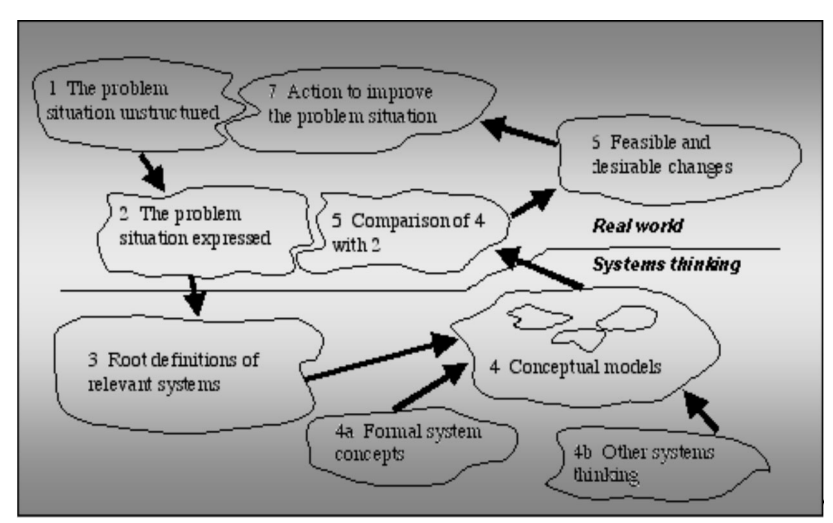

Figure 1. The seven stages of Soft System Methodology [3].
Our residency-education activity survey was performed through interviews and questionnaires. The six professors of the FMRP-USP academic body responsible for the training of the resident doctors and the three medicalresidency learning representatives, R1, R2 and R3, were interviewed. Seventeen (of the twenty-one residents of the college) had answered a questionnaire. The interviews and questionnaires were searched to establish how the residents' training is and what their experiences and expectations are in relation to educational computing environments. All professors and residents interviewed have personal computers with Internet access; they state that they always use the computer in their professional activities.

$75 \%$ of the residents had already had experience with distance education. The e-learning system is used in graduation and specialization as support in several disciplines. Through it, the students can download instructional material, participate in forums and receive acknowledgments and official notices. The complementary academic activity indicated by both residents and professors as the most important is called 'session for clinic/radiological/pathological correlation, CRP'. These approximately one-hour sessions are held daily and work as supervised consultation - a set of images from a clinical case is presented; then a resident is responsible for considering the clinical and differential diagnosis and treatment. The material used in these sessions is from the college academic archive, the Hospital Information System databases, or from the professor's personal-case archive.

The residents' suggestions for computational-teaching support were a system for considering examinations, a didactic database system, and a lessons-register system within the e-learning system. The professors' suggestions were a didactic database system, a research-support system, a system for considering cases with a studentevaluation register, a support system for the CRP sessions, video-lessons, e-learning courses on complementary subjects (like Information Technologies and Hospital Infection Control Practices), and computer-assisted evaluations. Some concerns and recommendations were a friendly interface system.

Due to its nature, the training at the service makes activity-planning and the schedule difficult. The volume and frequency of medical consultations are intense and, although this condition can be considered advantageous (for the amount and possible diversity of cases), generally, the instructors have an excessive workload. Thus, the preparation of the study material and the execution of the complementary academic activities demand careful organization, which is not always possible. Although the college presently has a broad $\mathbf{1 0 0} \%$ digital-format didactic-image base - accumulated since 1954 - it does not have an automated access and storage system.

A better definition of the evaluation criteria is seen by the residents as a way to receive feedback on his/her performance and validate his/her training. The CNRM and CBR norms define the minimum requirements for specialization in radiology and image diagnosis. Goals are imposed in these norms, such as time slicing between activities, types of examinations to perform, and the minimum number of procedures and/or finding-reports required per year for each resident's training, namely, 5000. However, they do not consider a pedagogical 
program with defined objectives neither do they establish phases for resident education, which could be used as a checkpoint.

\section{B. Stage 3-Root definitions}

Root or essential definitions are formulated by choosing a particular concise view of the situation, such as a group of factors that describe the nature of the situation, i.e. 'what the system is'. Initially, these definitions configure "what it is necessary to perform".

The essential definitions are called by Checkland [3,4] as CATWOE: Clients, Actors, Transformations, Worldview (or Weltanschauung), Owner, and Environment. In our case: Customers - resident doctors; Actors - professors and employees; Transformations imposed by a computerized teaching environment; Owner - is the community (the hospital is a public institution); Environment - the hospital school with all its complexity; and Worldview (Weltanschauung) - the hospital school must be as concerned with education activities as with professional activities. In general, it presents success in both activities. Besides the results in scientific research, it has the approval of the community in the region as well $[8,9]$.

The essential definitions are:

- More effective use of the computing resources for didactic purposes - there is enough infrastructure and interest to work in a computerized teaching environment;

- The education environment must be friendly - if the allocation of many hours for learning and especially for the maintenance of the education environment is necessary, there is the feeling that it will be abandoned;

- The education environment must be flexible necessity of time flexibility to dedicated one's self to complementary academic activities;

- The education environment must support evaluation - there is great concern regarding the training evaluation structure;

- The education environment must support complementary subjects - e-learning courses for complementary education such as bioethics, technology and epidemic control must be feasible;

- The education environment must structure the didactic archive - all professors, and about $60 \%$ of the students, suggested the need for improvement in the didactic archive infrastructure.

\section{Stage 4-Conceptual Modeling}

The conceptual model is a graphical representation (a frame) of the components necessary to reach changes indicated in the essential definitions. It must be tested to guarantee compliance with the following requirements: assure the criteria is a system, have integrated components, have a lasting purpose, have resources for performance measurement, have control process and decision support, be part of the system or environment with which it interacts, have decisions for the border processes, support itself, have the expectation of continuity and perpetuation. The conceptual model considered is schematized in Figure 2. The bases for this integrated environment are a tutor system for resident training in the formulation of a diagnosis, a didactic image database, a knowledge base, and an e-learning structure.

The Tutor Systems are being used in many teaching areas [10,11]. In radiology, Tutor Systems associated with Knowledge-Based Systems can capture the structured knowledge of the specialist and thus support the dynamic generation of training and error-identification routines. In the considered environment, the resident doctor will interact with a tutor system, supported by two pillars. The first one is a didactic image database, with or without confirmed diagnoses. This image database can receive data from the Hospital Information System or from the medical radiologist's personal database. The current didactic archive will be incorporated in this image database.

Concerning the medical-image storage systems, they are still being investigated, despite the fast-paced development. There have been proposals for the establishment of a standard data-registry and medicalimage indexation structure, like RadLex[12], these issues are relevant for storage and recovery of data from image examinations[13].

Working with images opens up another important technological front: the recovery of images based on Content-Based Information Retrieval (CBIR). The comparison of images from one exam with others that already have confirmed reports and diagnoses, when applied in several areas where the automated evaluation of the image content is relevant [14,15], provides broad support for the medical diagnosis. The automation of this process results in Computer Aided Diagnosis CAD $[16,17]$. Some CADs are important resources for diagnosis support, as in the case of mammographies, approved as a diagnostic resource in breast cancer by the FDA (USA Food and Drug Administration).

The Tutor System may or not demand CBIR processes, as illustrated in Figure 2. The tutorial system will be able to assist the resident doctor's training through the retrieval from the database of similar images for a query image for which the diagnosis is desired. The retrieved images would bring a description of the examination, findings and diagnoses. Since Content-Based Image Retrieval is highly dependent on the type of examination and the anatomical region, this option will be available when it has algorithms tested for its implementation.

On the other hand, the semantic structures from confirmed diagnoses or consultations are inserted into a knowledge database - as a second support pillar for the Tutorial System. This knowledge database will support the tutor system for the conclusion of similar diagnoses, like what happens in CRP sessions: description technique of the image, findings and diagnosis. The tutor system will have a basic structure; however, its implementation will incorporate the necessary and available components for each type of examination, anatomical region and pathology.

The knowledge database will be able to register shunting lines related to the resident in relation to the adequate routes to find the correct diagnosis as well. This feedback possibility and the factor identification that had caused such shunting refine the election of the image characteristics that identify the pathology, in contraposition to the ones that cause confusion and lack of 
precision in the result. This is an important subsidy to the research: to make use of cases with confirmed diagnoses in the training and keep a register of the attempts to reach them, allied to the complete definition of the ways used to reach the findings, could supply the elements to support research for CAD systems as much as for CBIR systems.

The interface system/users must be as simple and operational as possible. The choice to use an e-learning system is due to the familiarity that those involved already have with this software. The e-learning system can easily contain the complementary courses such as information technology, bioethics and hospital-infection control practices; only the definition of the contents and materials will be necessary.

Computer-assisted instruction in the consultations (Figure 2) consists of presenting a case image(s) and complementary information; the student will register the description of the image, findings and diagnosis in the system. These processes will feed a resident-evaluation database into e-learning systems.

This integrated system, with a didactic image database, a knowledge database and an e-learning interface, composes the educational computing environment in radiology and image diagnosis. The Considered Model has covered the essential definitions presented in section 3.2.

\section{Stage 5 - The 5 E's}

The 5 E's are: 1) Efficacy - do the means employed work? Do they reach the objectives? ; 2) Efficiency - are the resources used minimized? , 3) Effectiveness - Does the transformation help attain the long-term goals? ; 4) Ethic - are the changes morally acceptable? ; and 5) Elegance - do the changes work harmoniously? The conceptual model proposed was broadly discussed with the team of professors at the hospital school. The objectives were reached, because the model contemplates the expectation both of the students and the instructors, especially in regards to the characteristic availability of the e-learning and the difficulties in assessing students. All the projects developed, and being developed, that could be used as resources for the formation of the medical body were contemplated; the proposal infrastructure in terms of technological resources is compatible with the present one, ensuring the minimization of the resources. The effectiveness and ethic are met once the proposal support is in harmony with the lines of the ongoing researches at the college.

\section{E. Stage 6-Comparison}

Since the conceptual model produced is theoretical, it does not represent the system's actual or potential structure. A comparison or test with the real world is mandatory. This process will bring the necessary subsequent actions. Incompatibilities between the model and the real world must indicate problems and/or necessities of improvements. The product of this test phase is a list of corrective activities. The comparison of the proposed model defined the choice of the software listed in Table 1 and corrections already incorporated to the model in Figure 2.

\section{F. Stage 7-Actions}

The "Actions" will be defined in stage 7 . The points that were raised during stage 6 (comparison) must define the actions that will produce improvements. These actions must be identified and implemented and they can affect the structure, processes, procedures and attitudes in the system. The established actions are summarized in Table1. All related systems are being developed or adapted to be implemented in the proposed environment counting on the work of seven people, among professors and postgraduation students.

\section{RESUlTS AND CONCLUSION}

Medical images and their interpretations involve multidisciplinary knowledge and thus increase the complexity of medical-radiologist education. In this proposal, the tutor system, knowledge-database system, image database, contend-based image retrieval and elearning were used to compose the base for a Computational Environment for Radiology and Image Diagnosis Teaching.

The development of the model provided three important aspects that can be addressed immediately. First, is the identification of an available structure that can be used to the advantage of implementing e-learning courses for the complementary subjects; second, is the observation necessary for a more detailed training program with checkpoints that guide evaluations; finally, it is necessary for the development a didactic database system and tutor systems.

This study guides the proposal, which was approved by the staff, for the integration of several of the hospital school systems for the construction of an integrated environment for education in radiology.

TABLE I.

SYSTEMS IN DEVELOPMENT OR ADAPTED.

\begin{tabular}{|c|c|c|c|c|}
\hline & Component & System & $\begin{array}{c}\text { Main } \\
\text { Software }\end{array}$ & Status \\
\hline 1 & E-learning & $\begin{array}{l}\text { "Case-of-the- } \\
\text { Day” System: } \\
\text { Resident Training } \\
\text { and Assessment in } \\
\text { Image Diagnosis }\end{array}$ & $\begin{array}{l}\text { Tests with } \\
\text { Moodle }^{1} \text { and } \\
\text { TeleEduc }^{2}\end{array}$ & $\begin{array}{l}\text { In } \\
\text { develop- } \\
\text { ment }\end{array}$ \\
\hline 2 & $\begin{array}{l}\text { Didactic } \\
\text { Database }\end{array}$ & $\begin{array}{l}\text { FMRP-USP } \\
\text { Didactic-Archive } \\
\text { System }\end{array}$ & $\begin{array}{l}\text { RadLex }^{3} \text { and } \\
\text { tests with } \\
\text { MySQL }^{4} \text {, } \\
\text { PostGreSQL } \\
\end{array}$ & $\begin{array}{l}\text { In } \\
\text { develop- } \\
\text { ment }\end{array}$ \\
\hline 3 & $\begin{array}{l}\text { Tutor } \\
\text { System }\end{array}$ & $\begin{array}{l}\text { Tutor System for } \\
\text { MRI of Focal } \\
\text { Lesions in Normal } \\
\text { and Chronically } \\
\text { Diseased Liver }\end{array}$ & Prolog 6 & $\begin{array}{l}\text { In } \\
\text { develop- } \\
\text { ment }\end{array}$ \\
\hline 4 & CBIR & $\begin{array}{l}\text { MedCBIR-RF } \\
\text { [18] }\end{array}$ & $\begin{array}{l}\text { C++Builder }{ }^{\circledR} \\
\text {, v.5.0 and } \\
\text { Library C++ } \\
\text { GBDI } \\
\text { Arboretum }^{9}\end{array}$ & $\begin{array}{l}\text { In } \\
\text { Integra- } \\
\text { tion }\end{array}$ \\
\hline 5 & E-learning & $\begin{array}{l}\text { Collaborative } \\
\text { Education Using } \\
\text { the Internet }^{8}\end{array}$ & TeleEduc $^{2}$ & Design \\
\hline
\end{tabular}

1.http://moodle.org/

2.http://teleduc.nied.unicamp.br/ teleduc/pagina_inicial/index.php?\&cod_lin=

3.http://www.radlex.org/viewer

4.http://www.mysql.com/

5.http://www.pgsql.com/

6.http://www.swi-prolog.org/

7.Based on [20]

8.Based on [19]

9.http://gbdi.icmc.usp.br/downloads.php 


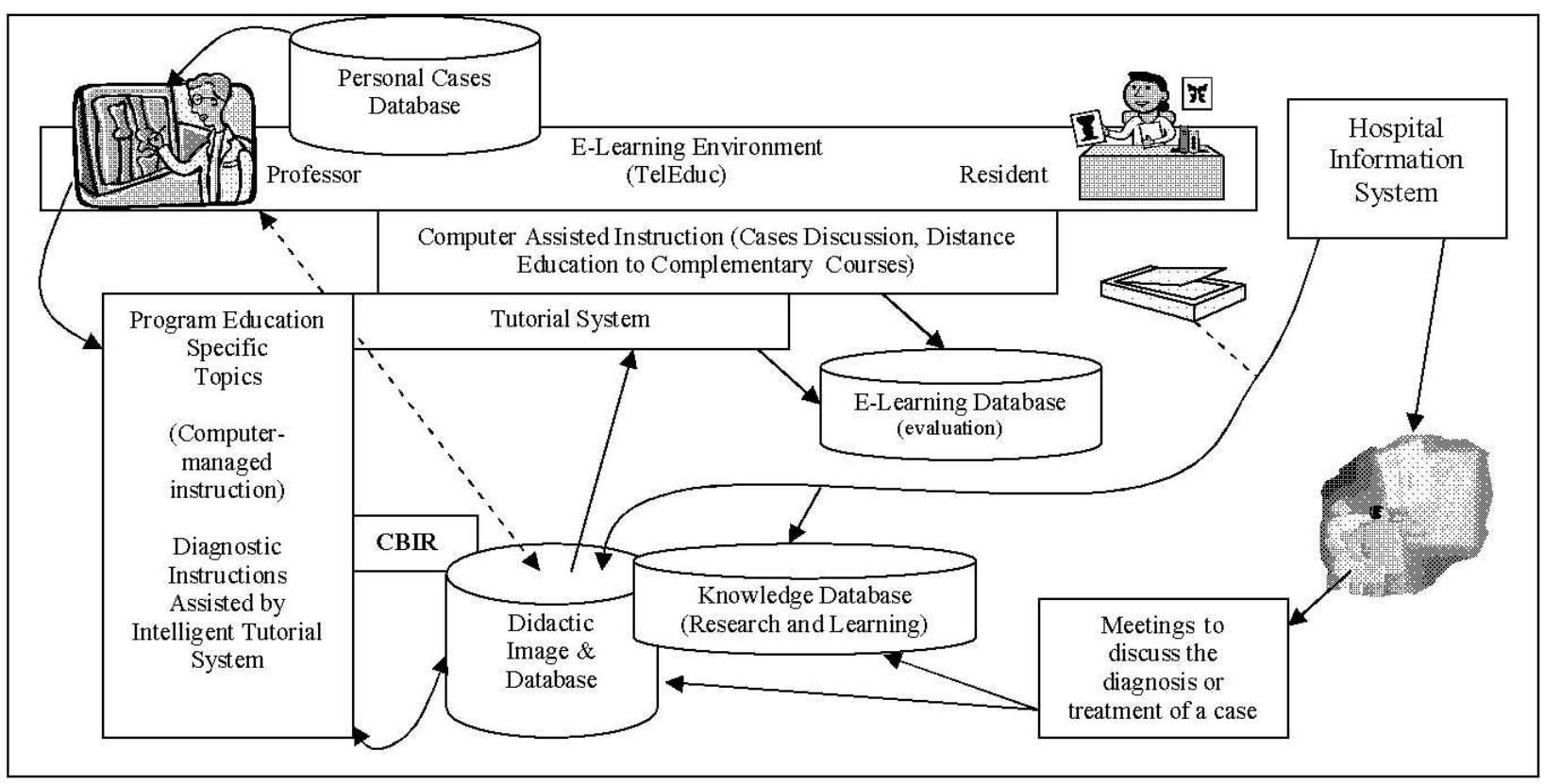

Figure 2. Conceptual Frame Proposed (SSM - Stage 4).

\section{REFERENCES}

[1] Boéchat A L, Sousa E G, Moreira F A, Koch H A, A Proposal for a Medical Residency Program in Radiology and Diagnostic Imaging (2007); Radiol Bras;40(1):33-37.

[2] Bertalanffy L, General system theory - A new approach to unity of science (1951), Human Biology, Vol. 23, p. 303-361.

[3] Checkland P. B., Systems Thinking, Systems Practice (1981), Wiley, Chichester,.

[4] Checkland P., Poulter J., Learning For Action: A Short Definitive Account of Soft Systems Methodology, and its use Practitioners, Teachers and Students (2006), ISBN: 978-0-470-02554-3.

[5] Pinheiro M G, Figueiredo L R, Cezarino L O, Martinelli D P; Using Soft Systems Methodology to Fight Against Info-Exclusion: The Experience of a Brazilian University (2006). Systemic Practice and Action Research, Volume 19, Number 5, pp. 429440, DOI 10.1007/s11213-006-9034-4. (doi:10.1007/s11213-0069034-4)

[6] Assimakopoulos N A, Theodosi A D; A Systemic Approach for Modeling Virtual Enterprise's Management Features (2003). Tamkang Journal of Science and Engineering, Volume 6, Number 2, pp. 87-101.

[7] Brasil. Legislation (Decreto $\mathrm{n}^{0} 80.281$ - 1977). Regulates the medical residence, creates the National Commission of Medical Residence and others. Brasília: DOU Diário Oficial da República Federativa do Brasil, 6/9/1977. Seção 1, pt 1, p. 11787. http://portal.in.gov.br/imprensa/menu/legislacao, access dez 26/2007.

[8] FAEPA Foundation of Support to Education, Searche and Assistance of the Hospital of the Clinics of FMRP-USP, Activities Report 2005, http://www.faepa.br/ , access jul 10/2008.

[9] HCRP Activities Report (2006) http://www.hcrp.fmrp.usp.br/gxp files/arqs/pdf/RelatórioAtividades2006.pdf access jul 10/2008.

[10] Kulik A, Chukhray A, Chukhray M. Diagnostic Models of an Intelligent Tutor System for Teaching Skills to Solve Algebaic Equations. iJET International Journal of Emerging Technologies in Learning, www.i-jet.org, vol 2, no 1, 2007.

[11] Suebnukarn S., Haddawy P.; A Collaborative Intelligent Tutoring System for Medical Problem-Based Learning (2004). ACM IUI’04, Funchal, Portugal, January, 13-16.

[12] RadLex: A Lexicon for Uniform Indexing and Retrieval of Radiology Information Resources. Radiological Society of North America RSNA. http://www.radlex.org/viewer, access jul $15 / 2008$.
[13] Siegel E. L., Current State of the Art and Future Trends, in Filmless Radiology (1999). Springer Verlag, New York City, pp. 3-20.

[14] Shyu M L; Chen S C; Chen M; Zhang C; Sarinnapakorn K; Content-based image retrieval for multimedia databases: Image database retrieval utilizing affinity relationships (2003). Proceedings of the first ACM international workshop on Multimedia databases, 78-95.

[15] Kinoshita SK, Azevedo-Marques PM, Pereira Jr. RR, Rodrigues JAH, Rangayyan RM (2007) Content-based retrieval of mammograms using visual features related to breast density patterns. Journal of Digital Imaging 20(2): 172-190. (doi:10.1007/s10278-007-9004-0)

[16] Pereira Jr R, Azevedo-Marques PM, Honda M O; Usefulness of Texture Analysis for Computerized Classification of Breast Lesions on Mammograms (2006). Journal of Digital Imaging, v. 1, p. 1-8, http://springerlink.com/content/h7305gt07564t835/?p=a39 c1a5c65b547088fcbf5185629d9d5\&pi=2; ISSN/ISBN: 08971889.

[17] Karam 0. H.; Hamad A. M.; Rady S. Enhancement of WaveletBased Medical Image Retrieval through Feature Evaluation Using an Information Gain Measure (2003). In ACM Symposium on Applied Computing Proceedings, Melbourne, Florida, pg 220 226, ISBN:1-58113-624-2.

[18] Azevedo-Marques, P. M. ; Rosa, N. A. ; Traina, A. J. M. ; Tranai Junior, C. ; Sérgio Koodi Kinoshita; Rangaraj Mandayam Rangayyan . Reducing the semantic gap in content-based image retrieval in mammography with relevance feedback and inclusion of expert knowledge. International Journal of Computer Assisted Radiology and Surgery, v. 1, p. 1-22, 2008.

[19] Monahan T., McArdle G.; Bertolotto M. CLEV-R: Design and Evaluation of an Interactive and Collaborative M-Learning Application, iJET International Journal of Emerging Technologies in Learning, www.i-jet.org, vol 2, no 2, 2007.

[20] Semelka, R C ; Voultsinos, V ; Altun, E ; Elias J Jr; MRI of Focal Lesions in Normal and Chronically Diseased Liver. In: Vincent B. Ho; Mark J. Kransdorf; Caroline Reinhold. (Org.). Body MRI Categorical Course Syllabus. Leesburg, VA: American Roentgen Ray Society, v. 1, p. 11-38, 2006.

\section{AUTHORS}

M. G. Pinheiro is studying for her $\mathrm{PhD}$ in the Faculty of Medicine of Ribeirão Preto, University of São Paulo, Brazil, development a computational environment for radiology and image-diagnosis teaching. (e-mail: mariliapinheiro@usp.br). 
L. R. Figueiredo is studying for his $\mathrm{PhD}$ in the Faculty of Medicine of Ribeirão Preto, University of São Paulo, Brazil, development a computational environment for radiology and image-diagnosis teaching. (e-mail: luisrica@terra.com.br).

P. M. Azevedo-marques is with Image Science and Medical Physics Center, Internal Medicine Department, Faculty of Medicine of Ribeirão Preto, University of São Paulo, Avenida dos Bandeirantes, 3900, 14048-900,
Ribeirão Preto, SP, Brazil (e-mail: pmarques@fmrp.usp.br).

J. Elias $\mathbf{J r}$ is with Clinical Medicine Department, Faculty of Medicine of Ribeirão Preto, University of São Paulo, Avenida dos Bandeirantes, 3900, 14048-900, Ribeirão Preto-SP, Brazil (e-mail: jejunior@fmrp.usp.br).

Manuscript received 31 August 2008. Published as submitted by the authors. 